\title{
DO POSTERIOR TEETH SUPRA-ERUPT WHEN OPPOSITE RESECTED SEGMENTS HAVE NOT BEEN PROSTHETICALYY RESTORED?
}

\author{
Arieh Shifman ${ }^{1 a}$, Shlomo Calderon ${ }^{2 b^{*}}$ \\ 'Department of Oral Rehabilitation, Sackler School of Medicine, Tel Aviv University, Tel Aviv, Israel \\ 2Department of Oral and Maxillofacial Surgery, Rabin Medical Center, Beilinson Hospital, Petah Tikva, Israel \\ ${ }^{a} \mathrm{DMD}$, Senior Clinical Lecturer \\ ${ }^{b} \mathrm{DMD}$, Professor
}

Presented by Prof. Shlomo Calderon before the International College of Prosthodontists, Biennial Congress Torino, Italy, September 2013

Academic Editor: Heinz Kniha, DDS, MD, PhD, Associate Professor, Ludwig-Maximilians- München University, München, Germany

\section{Cite this article:}

Shifman A, Calderon S. Do posterior teeth supra-erupt when opposite resected segments have not been prosthetically restored? Stoma Edu J. 2017;4(1):60-65

\section{ABSTRACT \\ DOI: 10.25241/stomaeduj.2017.4(1).art.6}

Introduction: The aim of this study was to assess the rate and timing of possible supra-eruption of posterior teeth opposing resected segments in a select maxillofacial group of postsurgical patients. Methodology: Twenty patients were included. 16 underwent simultaneous segmental mandibular resections and iliac bone graft reconstructions. The remaining 4 had partial maxillary resections with primary closure of the defect. No patient received any prosthetic restoration. Clinical photographs and radiographs at the last follow-up examinations were compared by superimposition to those obtained initially (mean 6.9 years).

Results: The results of this longitudinal retrospective study showed that not even slight supraeruption had occurred in any of the 16 patients.

Conclusion: These findings are discussed with regard to their possible cause and prosthodontic implications.

Keywords: super-eruption, supra-eruption, occlusion, unopposed molars, resected segments.

\section{Introduction}

Postsurgical maxillofacial patients occasionally remain without further prosthetic treatment. Patients may prefer not to undergo restorative treatment for a variety of reasons, including lack of perceived esthetic impairment where only posterior segments are involved, limited functional impairment, reluctance to undergo additional surgery and also for reasons of financial constraints.

In a study reporting on a group of 28 patients who underwent ablative tumor surgery and mandibular reconstructions with osseocutaneous fibula free flap 13 patients were postoperatively rehabilitated with implant-supported prostheses, whereas 18 patients had no dental prosthetic rehabilitation. ${ }^{1}$ These authors conclude that oral functions such as speech, diet tolerance and oral competence were not directly affected by the presence of prosthetic restorations. A decisive factor affecting oral function in these patients was the extent of soft-tissue loss.

In lieu of the accepted notion that the presence of molar teeth is essential for proper masticatory function and occlusal stability, ${ }^{2-4}$ the shortened dental arch (SDA) concept emerged as paradigm shift, namely that two bilateral pairs of occlusal contacts (premolar occlusion) are sufficient for these functions. ${ }^{5-7}$ Studies have shown that no marked adverse outcome has been displayed in SDA cases, such as temporomandibular (TM) overloading and TM disorders or parameters related to occlusal stability in the SDA arch (interdental spacing in the premolar area, overbite, increased wear of the remaining anterior teeth, or loss of alveolar bone supporting these teeth. ${ }^{5-7}$

Nonetheless, little attention has been given in the literature to possible supra-eruption (SE) of molar teeth in the opposing dental arch. Kiliaridis et al. ${ }^{8}$ examined 84 unopposed molars in 53 patients 
and found that 15 teeth (18\%) revealed no signs of SE, 49 teeth (58\%) displayed SE of less than $2 \mathrm{~mm}$, whereas 20 teeth (24\%) showed moderate to severe SE. Craddock and Youngson' ${ }^{9}$ examined 155 unopposed sites in 120 subjects and found the rate of SE in $83 \%$ of the sites. However, in both studies, the pattern of missing teeth was ill-defined and probably not displaying SDA situations.

In a questionnaire study of 200 Swedish dentists presented with a drawing of an SDA in the mandible in a virtual case, $85 \%$ of them suggested that marked SE of the maxillary molars would occur, whereas $13 \%$ believed in minor changes. ${ }^{10}$ In a large sample of patients with SDA and extreme SDA, Sarita et al. found that SE of unopposed teeth was absent or mild in $12 \%$, severe in $32 \%$ and to the opposing residual ridge (severe SE) in $56 \%$ of the subjects. ${ }^{11}$ However, the authors did not provide data with regard to the pattern of posterior tooth loss, though alluding to gradual tooth loss in their study.

The aim of the present study was to assess the rate and timing of possible SE of unopposed posterior teeth in a select group of postsurgical patients.

\section{Methodology}

\subsection{Subjects}

The study group included consecutive patients who were hospitalized in the Department of Oral and Maxillofacial Surgery, Beilinson Campus, Rabin Medical Center, Israel, during the 19902009 period. The study protocol was reviewed and approved by the Rabin Medical Center Institutional Ethical Committee and in accordance with the Helsinki Declaration of 1975, as revised in 2000.

Medical data such as clinical photographs, radiographs, type of surgical procedures and histopathological findings, were gleaned from hospital records. The inclusion criteria were: (1) surgical resection of a tumor in a posterior region of one of the jaws limited to bone and attached soft tissues; (2) immediate mandibular reconstruction of non-continuity defects or alternatively, primary surgical closure of a maxillary defect; (3) no adjuvant therapy such as radiation therapy or chemotherapy; (4) no signs of temporomandibular disorders; (5) sound dentition with minimal restorations; (6) normal occlusion with good intercuspation; (7) no postoperative prosthodontic treatment and (8) keeping long-term follow-up visits.

\subsection{Diagnostic evaluation}

The complete evaluation of each patient was made at the preoperative stage. Frontal and lateral views of the face of the patient was photographed using a Nikon SLR regular end digital camera with 1:1 macro lens (105/2.8 Nikon macro lens focusing at 1.2 meters). Intraoral photographs of the dentition in maximal intercuspation and semi-open position were taken at a distance of $30 \mathrm{~cm}$ with 22 lens aperture with the same camera. Other imaging modalities such as CT, MRI, ultrasonography or angiography were rarely indicated for a complete evaluation of the individual patient and have not been used in this study. Initial and follow up orthopantomographic radiographs were obtained for all cases.

\subsection{Surgical procedures}

In the mandible, under general anesthesia via using a naso-endotracheal intubation, segmental resection of the lesion was carried out by the combined intra and extraoral approach (modified Risdon or submandibular approach). Intraoral wounds were closed by watertide locking and interupted sutures. Mandibular fragments were positioned by maxillo-mandibular fixation in maximal intercuspation, secured by Eric arch bars. Mandibular continuity was restored by using titanium reconstruction plates (DePuy Synthes Companies, West Chester, PA 19380, USA; Stryker Global Headquarters, Kalamazoo, MI 49002, USA). Full body or hollow screws were used to secure the fixation of mandibular stumps. ${ }^{12,13}$ Corticocancellous particulate bone was harvested from the anterior iliac crest ${ }^{14}$ supported by a crib-form allogenic split rib. ${ }^{15}$ Soft tissues were closed by layers. In the maxilla, using oro-endotracheal intubation for general anesthesia, the lesion was resected in toto. Primary surgical closure of soft tissues was carried out, either by exploiting the buccal pad of fat or by a palatal rotated mucoperiosteal flap or a combination of both was used to facilitate closure. In the vast majority of patients, healing was uneventful, albeit in few patients healing was prolonged but complete; healing was spontaneous with the help of (or using) antiseptic irrigations $(0.2 \%$ chlorhexidine gluconate).

\subsection{Recall and documentation}

Postoperatively, patients were placed on a regular recall schedule namely, once every 3 months for the first year and thereafter once a year.

Complete evaluation was made at the preoperative diagnostic stage.

Clinical photographs and radiographs at the last recall visit were compared to those obtained initially. Photographed slides were scanned by Umax Power Lock II scanner and some of the older slides were copied by Nikon - E 28 Slide Copying Adapter. Radiographs were scanned and superimposed on PC graphic program and the degree of supra eruption of the unopposed segments evaluated.

\section{Results}

Twenty patients who were found to fulfill the inclusion criteria were included in the study, namely sixteen with mandibular involvement (Table 1) and 4 patients with maxillary involvement. (Table 2). The age of the patients ranged from 7 to 61 (mean 29.4) in the mandibular group and from 11 to 61 (14.2) in the maxillary group. In most patients ameloblastoma or its variants appeared as a primary tumor of the jaws. In contrast as a primary soft tissue pathosis, patients afflicted by squamous cell carcinoma could not be enrolled in 
Table 1. Mandibular Reconstruction Cases.

\begin{tabular}{|c|c|c|c|c|c|c|c|}
\hline No. & Name & Age (yrs) & M/F & Diagnosis & $\begin{array}{c}\text { Resection } \\
\text { Site } \\
\text { Location }\end{array}$ & $\begin{array}{c}\text { Distal } \\
\text { Tooth }\end{array}$ & $\begin{array}{c}\text { Follow } \\
\text { up (yrs) }\end{array}$ \\
\hline 1 & S.L. & 7 & M & $\begin{array}{c}\text { Ameloblastic } \\
\text { fibroodontoma }\end{array}$ & RT mand & 45 & 13 \\
\hline 2 & S.D. & 10 & M & $\begin{array}{c}\text { Ameloblastic } \\
\text { fibroodontoma }\end{array}$ & RT mand & 43 & 13 \\
\hline 3 & S.S. & 10 & M & Ossifying fibroma & RT mand & 45 & 7 \\
\hline 4 & C.E. & 20 & M & Blast injury & LT mand & 33 & 11 \\
\hline 5 & Y.A. & 20 & F & Ameloblastoma & $\begin{array}{c}\text { RT mand + } \\
\text { condyle }\end{array}$ & 41 & 14 \\
\hline 6 & K.Y. & 20 & M & Odontogenic keratocyst & RT mand & 45 & 7 \\
\hline 7 & C.Y. & 22 & F & Ameloblastoma & LT mand & 33 & 3.5 \\
\hline 8 & A.G. & 26 & M & Ameloblastic fibroma & RT mand & 43 & 12 \\
\hline 9 & SH.T. & 30 & F & Giant cell tumor & RT mand & 41 & 10 \\
\hline 10 & G.E. & 32 & M & Ameloblastoma & LT mand & 35 & 2.2 \\
\hline 11 & C.B. & 33 & F & Ameloblastoma & LT mand & 33 & 13 \\
\hline 12 & D.S. & 38 & F & Ameloblastoma & $\begin{array}{c}\text { RT mand }+ \\
\text { condyle }\end{array}$ & 42 & 5 \\
\hline 13 & R.A. & 40 & F & Aneurismal bone cyst & RT mand & 44 & 10 \\
\hline 14 & V.E. & 42 & F & Ameloblastoma & LT mand & 33 & 2.3 \\
\hline 15 & S.O. & 59 & F & Mucoepidermoid & LT mand & 35 & 4 \\
\hline 16 & R.Y. & 61 & M & Giant cell tumor & LT mand & 31 & 7 \\
\hline
\end{tabular}

Table 2. Maxillary Reconstruction Cases.

\begin{tabular}{|c|c|c|c|c|c|c|c|}
\hline No. & Name & Age (yrs) & M/F & Diagnosis & $\begin{array}{c}\text { Resection } \\
\text { Site } \\
\text { Location }\end{array}$ & $\begin{array}{c}\text { Distal } \\
\text { Tooth }\end{array}$ & $\begin{array}{c}\text { Follow } \\
\text { up (yrs) }\end{array}$ \\
\hline 1 & B.A. & 11 & F & $\begin{array}{c}\text { Ameloblastic } \\
\text { fibroodontoma }\end{array}$ & RT max & 13 & 9 \\
\hline 2 & C.M. & 14 & F & $\begin{array}{c}\text { Ameloblastic } \\
\text { fibroodontoma }\end{array}$ & LT max & 23 & 10 \\
\hline 3 & K.Y. & 16 & M & Sialoodontogenic cyst & RT max & 13 & 4 \\
\hline 4 & M.M. & 16 & F & Odontogenic myxoma & LT max & 22 & 10 \\
\hline
\end{tabular}

this study. The results of this study showed that not even slight SE had occurred in any patient. This is seen in examples of cases in Figs 1-5. The condition of the temporomandibular joints was not evaluated.

\section{Discussion}

The results of this long term retrospective study were unexpected. Super eruption had not occurred apparently even slightly in any single patient regardless of the age of the patient, the location and extent of the surgical resection and the follow up period.
These results are in contrast with those obtained by Sarita et al. ${ }^{11}$ However, in their study tooth loss was gradual, whereas in our study loss of teeth occurred in a single surgical procedure. As a result, the tongue could immediately fill the intraoral space created. It is conjectured that the lateral aspect of the dorsum of the tongue came into contact with the occlusal surface of the posterior teeth and prevented their subsequent eruption. Stabilization of the mandible during swallowing that is normally affected by the occlusal intercuspal contact is affected by closure onto the interposed tongue. 


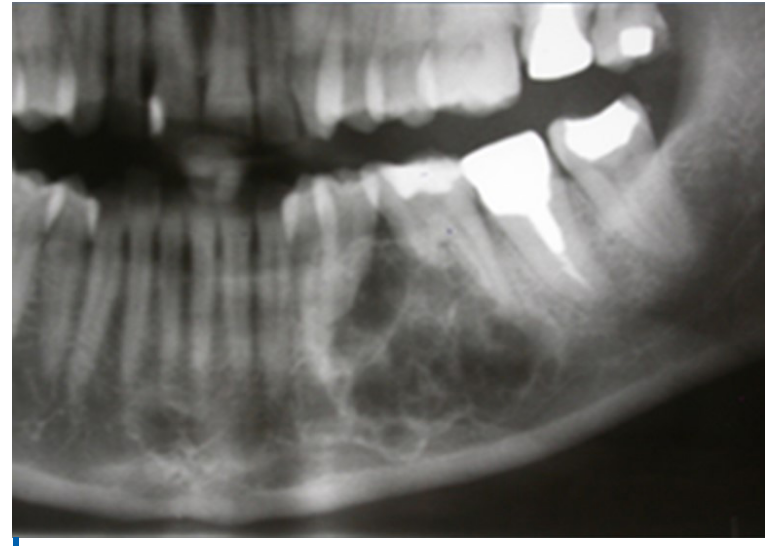

Figure 1. Ameloblastoma.

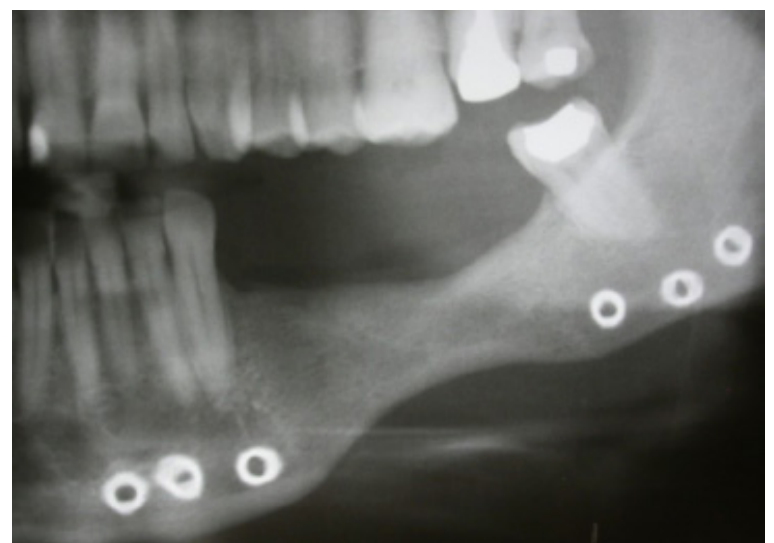

Figure 3. Six years post-operative. No supra-eruption of the teeth opposing the resected section.

Moreover, it seems that the ventral surface of the tongue can also function in this manner preventing super eruption of mandibular teeth. It is noteworthy that super eruption did not occur in patients were the surgical reduction extended beyond the definition of the SDA to include premolars, canines and even the incisor teeth. These situations may be considered as unilateral ultra-shortened dental arches. Even in patients who underwent partial glossectomies, the remaining tongue appeared to preserve oral function and hinder super eruption. However, prosthetically augmenting the palate for lowering the occlusal plane and thus enabling the remaining tongue to keep the bolus over the dorsal surface, is still advocated in some patients. ${ }^{16}$ Further lowering the occlusal plane may bring it below the maximum ability of the buccinators contraction. ${ }^{17}$

To summarize, within the limits of this study, restoration of the posterior jaw defects merely for prevention of future super eruption appears unjustified. Thus the time-old principle by DeVan "Our objective should be the perpetual preservation of what remains rather than the meticulous restoration of what is missing." is still valid. ${ }^{18}$

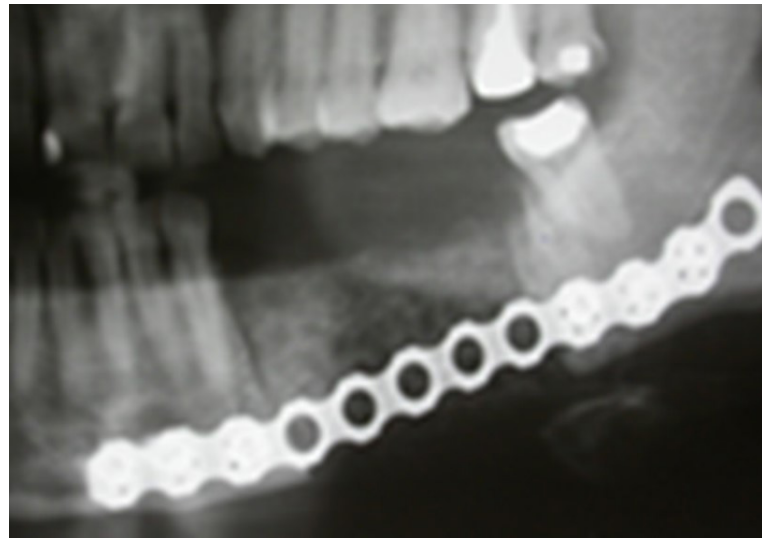

Figure 2. Six Months post-operative. Repair with split rib and reconstruction plate.

\section{Conclusion}

Posterior teeth opposing unrestored resected segments of the maxilla or mandible did not supraerupt over long periods of time. It is speculated that the interposition of the tongue to brace the mandible on swallowing prevents the unopposed molars and premolars from supra-erupting.

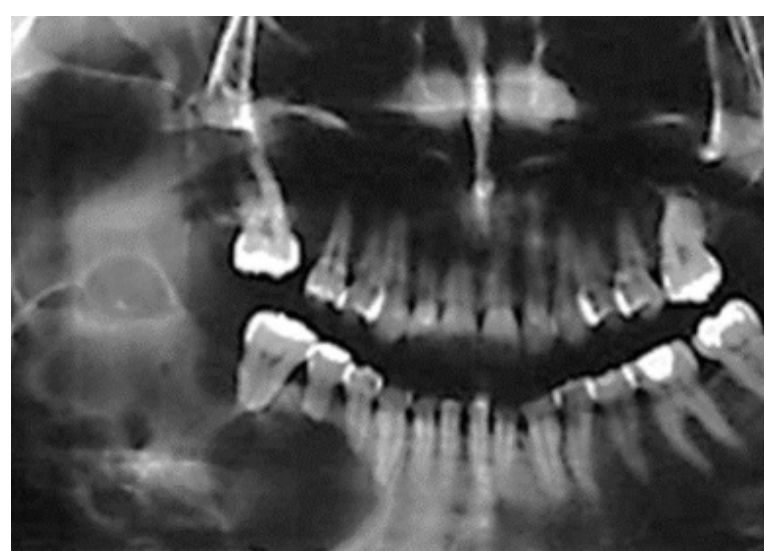

Figure 4. Ameloblastoma. Treated by hemi mandibulectomy and restored with split rib and reconstruction plates.

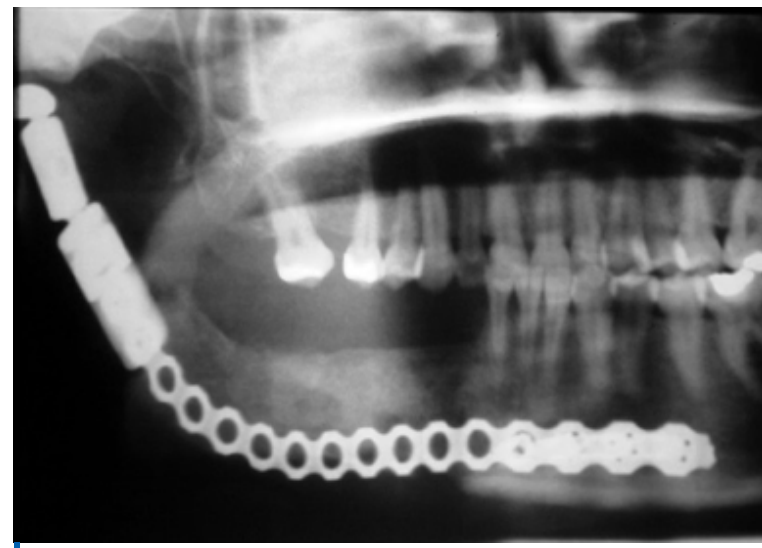

Figure 5. Twenty two years post operative. No supraeruption of the unopposed maxillary teeth opposite the resected segment. 


\section{Acknowledgments}

The authors declare no conflict of interest related to this study. There are no conflicts of interest and no financial interests to be disclosed.

\section{References}

1. lizuka T, Häfliger J, Seto I, et al. Oral rehabilitation after mandibular reconstruction using osteocutaneous fibula free flap with endosseous implants. Factors affecting the functional outcome in patients with oral cancer. Clin Oral Implants Res. 2005;16(1):69-79.doi: 10.1111/j.1600-0501.2004.01076.x

[Full text links] [PubMed] Google Scholar (74) Scopus (57)

2. Beyron H. Optimal occlusion. Dent Clin North Am. 1969;13(3):537-554.

[PubMed] Google Scholar (208) Scopus (85)

3. Devlin H, Wastell DG. The mechanical advantage of biting with the posterior teeth. J Oral Rehabil. 1986;13(6):607-610.

[Full text links] [PubMed] Google Scholar (14) Scopus (9)

4. Mohl ND, Zarb GA, Carlson GE, Rugh JD. A Textbook of Occlusion. Chicago: Quintessence Publishing Co.; 1989:174, 182.

5. Witter DJ, Creugers NH, Kreulen CM, de Haan AF. Occlusal stability in shortened dental arches. J Dent Res. 2001;80(2):432-436. doi: 10.1177/00220345010800020601 [Full text links] [PubMed] Google Scholar (138) Scopus (63)

6. Armellini D, von Fraunhofer JA. The shortened dental arch: a review of the literature. J Prosthet Dent. 2004;92(6):531-535. doi: 10.1016/ S002239130400530X. Review.

[Full text links] [PubMed] Google Scholar (128) Scopus (56)

7. Walther W. The concept of a shortened dental arch. Int J Prosthodont. 2009; 22(5):529-530.

[Full text links] Google Scholar (8) Scopus (1)

8. Kiliaridis S, Lyka I, Friede H, Carlsson GE, Ahlqwist M. Vertical position, rotation, and tipping of molars without antagonists. Int J Prothodont. 2000;13(6):480486.

[PubMed] Google Scholar (75) Scopus (38)

9. Craddock $\mathrm{HL}$, Youngson CC. A study of the incidence of overeruption and occlusal interferences in unopposed posterior teeth. Brit Dent J. 2004;196(6):341-348; discussion 337. doi: 10.1038/ sj.bdj.4811082

[Full text links] [PubMed] Google Scholar (53) Scopus (24)
10. Lyka I, Carlsson GE, Wedel A, Kiliaridis S. Dentists' perception of risks for molars without antagonists. A questionnaire study of dentists in Sweden. Swed Dent J. 2001;25(2):67-73.

[PubMed] Google Scholar (22) Scopus (13)

11. Sarita PT, Kreulen CM, Witter DJ, van't Hof M, Creugers NH. A study on occlusal stability in shortened dental arches. Int J Prosthodont. 2003;16(4):375-380.

[PubMed] Google Scholar (80) Scopus (29)

12. Raveh J, Sutter F, Hellem S. Surgical procedures for reconstruction of the lower jaw using the titaniumcoated hollow-screw reconstruction plate system: bridging of defects. Otolaryngol Clin North Am. 1987;20(3):535-558.

[PubMed] Google Scholar (100) Scopus (39)

13. Vuillemin T, Raveh J, Sutter F. Mandibular reconstruction with the THORP condylar prosthesis after hemimandibulectomy. J Craniomaxillofac Surg. 1989;17(2):78-87.

[PubMed] Google Scholar (18) Scopus (7)

14. Burstein FD, Simms C, Cohen SR, Work F, Paschal M. Iliac crest bone graft harvesting techniques: a comparison. Plast Reconstr Surg. 2000;105(1):34-39. [Full text links] [PubMed] Google Scholar (89) Scopus (63)

15. Marx RE, Kline SN, Johnson RP, et al. The use of freeze-dried allogenic bone in oral and maxillofacial surgery. J Oral Surg. 1981;39(4):264-274. [PubMed] Google Scholar (73)

16. Marunick $M$, Tselios $N$. The efficacy of palatal augmentation prostheses for speech and swallowing in patients undergoing glossectomy: a review of the literature. J Prosthet Dent. 2004; 91(1):67-74. Review. doi: 10.1016/S0022391303007352

[Full text links] [PubMed] Google Scholar (57) Scopus (31)

17. Berry DC. The buccinator mechanism. J Dent. 1979;7(2):111-114.

[PubMed] Google Scholar (6) Scopus (4)

18. DeVan MM. The nature of the partial denture foundation: Suggestions for its preservation. J Prosthet Dent. 1952; 2(2):210-218. doi: 10.1016/0022-3913(52)90048-6 Google Scholar (99) Scopus (45)

\section{Arieh SHIFMAN \\ DMD, Senior Clinical Lecturer Department of Oral Rehabilitation Sackler School of Medicine Tel Aviv University, Tel Aviv, Israel

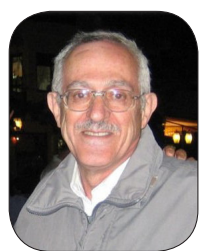

He graduated from the Hadassah Dental School Jerusalem (DMD). He got his advanced Education at Sloane Kettering USA specializing in Maxillofacial Prosthodontics and Prosthodontics. He is Head of the IDF Dental Prosthetic unit. He is also Chief Consultant in Maxillofacial Prosthodontics and Temporomandibular Disorders at the Beilinson Hospital Petach Tikva. He is Head of the Prosthodontics and Prosthodontic graduate program IDF. He is also Honorary member of the International College of Prosthodontists. 


\section{orestions}

\section{A "shortened dental arch" is defined as:}

a. An arch from canine to canine;

b. An arch missing molar teeth;

c. The presence of two bilateral pairs of occlusal contacts (premolar occlusion);

$\square \mathrm{d}$. The presence of 10 teeth per arch contacting each other.

\section{Immediate bony reconstruction of a posterior segmental mandibular resection, without replacement of the lost teeth, leads to:}

a. Supra-eruption of the unopposed molars;

b. No supra-eruption of the unopposed molars;

c. Earlier loss of remaining teeth due to increased wear;

$\square$ d. Bilateral increase of the curve of Spee.

\section{Which is not a possible adverse outcome of a shortened dental arch?}

a. Bruxism;

b. Increased wear of the remaining anterior teeth;

c. Interdental spacing in the premolar area;

$\square$ d. Temporo-mandibular-joint overload.

\section{After ablative surgery with immediate bony reconstruction, supra-eruption of unopposed} teeth is avoided because of:
a. Old age;
b. Follow-up visits;
c. Tongue interposition;
$\square$ d. Absence of any tooth filling.

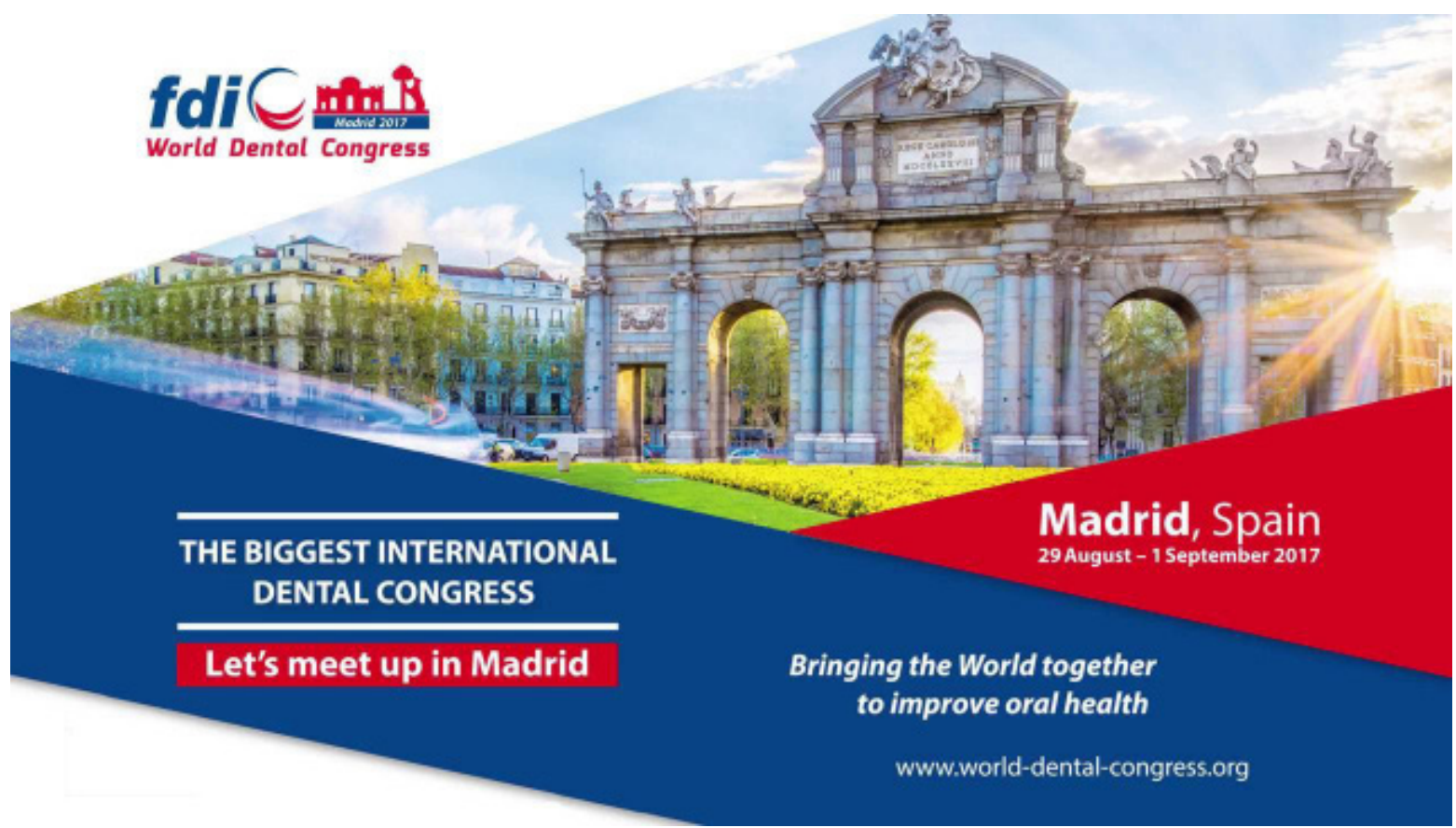

